\title{
Organizational Effectiveness: An Alternative Perspective ${ }^{1}$
}

\author{
GREGORY H. GAERTNER \\ S. RAMNARAYAN \\ Case Western Reserve University
}

\begin{abstract}
A paradigm is proposed that views effectiveness as the ability of an organization to account successfully for its outputs and operations to its various internal and external constituencies. This framework can be used to assess effectiveness by examining organizational outputs and processes in a critical and holistic way. A review of the existing literatures on organizational effectiveness and a case example are used to develop the proposed framework.
\end{abstract}

In the early 1970 s, one of the major program emphases of the Environmental Protection Agency was to give grants to municipalities to construct sewage treatment facilities. This program consistently accounted for upwards of 70 percent of the agency's total funding until the 1982 fiscal year budget. In that budget, amid much controversy, the funding for this program was slashed. Judging from interviews and published documents, there is little reason to believe that major changes in the way the program operated had occurred to call down either criticism or the budget knife. Did a program that apparently had operated successfully for more than a decade suddenly become ineffective?

This example is far from unique in the federal sector or among organizations in general today. Moreover, existing literature on organizational effectiveness gives few tools to explain how dramatic shifts in the evaluation of organizations can occur without similarly drastic changes in the organization's activities.

This paper proposes a framework for under-

'The research for this paper was supported by the U.S. Office of Personnel Management, Contract \#OPM 23-80. The authors would like to acknowledge the help received from Karen Gaertner, David Akinnusi, Richard Cogan, James Collins, Toni Denton, Irene Devine, Allan Plath, and Juliann Spoth, who parlicipated in a brainstorming session to generate ideas for looking at effectiveness. Also, thanks to Darlene Wolf for her patient editorial assistance. standing transformations both in how organizations do their work and how they account for the work they do. It is argued that effectiveness in organizations is not a thing, or a goal, or a characteristic of organizational outputs or behaviors, but rather a state of relations within and among relevant constituencies of the organization. An effective organization is one that is able to fashion accounts of itself and its activities in ways in which these constituencies find acceptable. By implication, effectiveness is not a state but rather a process; it is a characteristic of relations and not outputs; it is negotiated rather than produced. Effectiveness inheres only partly in bottom line figures. A fuller apprehension of it requires an understanding of why and for whom this (or any) particular set of bottom line figures was produced, and of the institutional vision and logic that support this account of the organization to its constituents. The approach here is to view effectiveness as the ability of an organization to account successfully for its outputs and operations to its various internal and external constituencies.

\section{Existing Literature}

A review of the existing literature on organizational effectiveness reveals that the different definitions and approaches can be characterized by two major dimensions: (1) Focus of the definition. 
Some definitions focus on measures of terminal outcomes, such as profitability, survival, or goal attainment. Others tend to be more concerned with organizational processes and structures. (2) Intended use of the concept. There are approaches that tend to be organization-specific. Others are intended for a generality of organizations. The latter studies aim for general propositions about either outputs or organizational processes and structures. The former utilize the detail available to explain events in a given organization or class of organizations in a less generalizable way. These two dimensions, when cross-classified, result in four distinct types of approaches, as proposed in Figure 1.

\section{General Output Measures (Cell I)}

One set of approaches included in Cell I of Figure 1 uses the traditional accounting measures, such as productivity, profit, or return on investment as criteria for effectiveness (Price, 1968). The second set of approaches focuses on organizational health and survival as the ultimate organizational outcome. Some of the recent impetus for this approach has come from authors whose theoretical perspectives are rooted in population ecology (Aldrich, 1979; Hannan \& Freeman, 1978; McKelvey, 1980).

These approaches, which rely solely on general measures of output, labor under several difficulties. Different organizations produce different things, as do even different subunits in the same organization. Metrics that can convert these outputs into comparable units across or even within organizations are not always available. Thus subunits, such as personnel and production control departments and personnel occupying staff and even managerial positions, produce outputs that are not easily quantified and are only indirectly related to most terminal outputs.

Second, the multiplicity of outputs produced by the organization results in their being differently valued by different constituencies of the organization (Friedlander \& Pickle, 1968; Scott, 1977). From different perspectives different views of the effectiveness of a given organization are obtained. Under such circumstances, to decide, by legal or theoretical fiat, which outputs really matter does a dissservice to the complexity and diversity of organizations. Because the general measures of outputs have these problems in abstraction and applicability, one alternative has been to focus not on outputs of a general nature, but rather on the outputs of particular organizations of interest.

\section{Organization-Specific Output Measures (Cell II)}

Goal-centered approaches to organizational effectiveness can be considered in this cell. Within this orientation, effectiveness would be assessed by how well the goals of the organization are being achieved. Organizational goal attainment yields valuable insights about the organization's character and behavior (Etzioni, 1964; Perrow, 1970), be. cause serious goal setting represents an attempt at optimization of potentially conflicting organizational factors, in light of particular past and present circumstances and desired future. Thus, goal-centered approaches provide a useful degree of detail and context often lacking in general output mea. sures, at the expense of some generality in findings.

But analysis of goal attainment for evaluating organizational effectiveness has several limitations.

\section{Figure 1 \\ Approaches to Organizational Effectiveness}

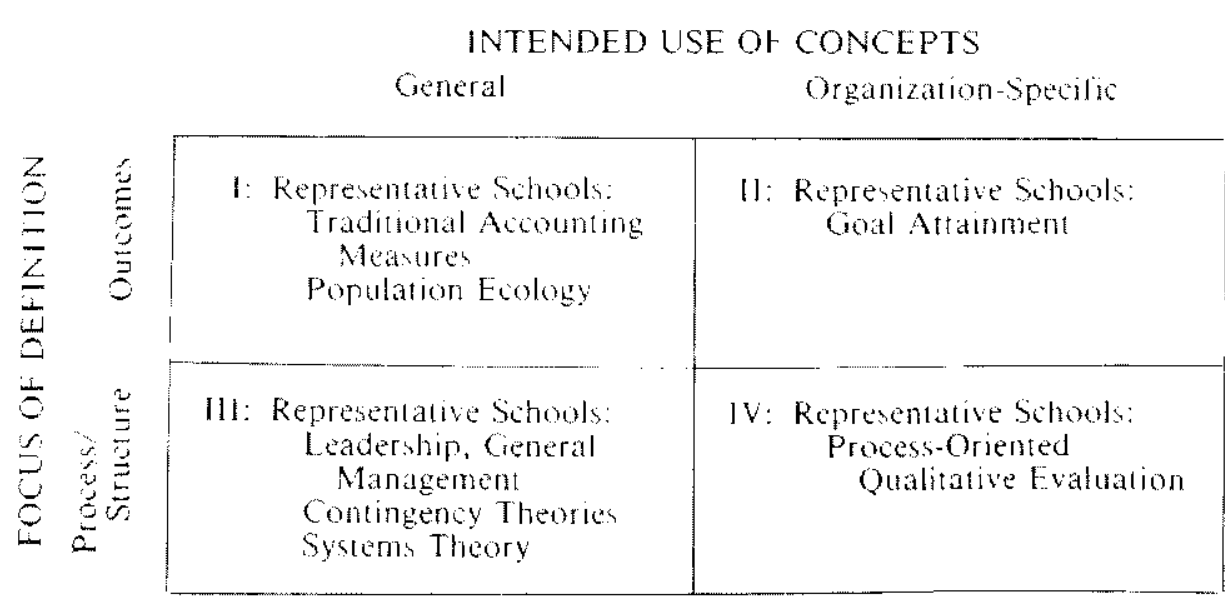


First, goals for programs and organizations are dynamic and are likely to change over time, partly as reflections of changing external circumstances and partly due to changes in the political makeup of the organization itself (Bardach, 1977; Kahn 1977). Second, there is the problem of interpreting the uses of goals in organizations. In some cases goals are treated as window dressing, designed not to orient the behavior of organizational members, but rather to provide only symbolic recognition to some con. stituency (Galbraith, 1967; Hannan \& Freeman, 1977). In other cases they are seen not as actual targets to be aimed for, but rather internal messages within the organization of what behavior is hoped for (Granick, 1967). Third, Weick (1979) notes that goals in organizations frequently are inventions 10 suit activity already performed - they are or become the organization's means of restructuring a rationale for past activity.

One problem common to both organization-specific and more general approdches to organizational effectiveness can easily be seen. Whatever the outputs finally arrived at, an understanding of effectiveness must include not only these outputs, but also an understanding of the factors that are associated with their production. In the absence of such understanding, any output measure of effectiveness is simple but barren-clear in its measurement, but inadequate in utility. Unless theories of effectiveness reach back into the processes, structures, and intentions that are associated with it, litile can be said about what to do to improve the effectiveness of organizations. As a result, theoretical focus has shifted to organizational processes and structures which either in the general case or in specific cases, can be shown to be associated with the effective provision of outputs.

\section{General Measures (Cell III)}

Much of the recent popular and academic literature on management style (Blake \& Mouton, 1964 ; Etzioni, 1964; McGregor, 1960), leadership (Fiedler \& Chemers, 1974), decision making (Kepner \& Tregoe, 1981), and organizational structure (Chandler, 1976; Galbraith, 1973) focuses on generally effective or contingently effective aspects of organizations. These theories argue that for some or all organizations, it is possible 10 specify aspects of organizational activity that are likely to improve organizational effectiveness. For some of these. there is the tlat statement of good ways to manage or organize. Increasingly, however, these flat statements are discarded in favor of treatments that take into account relevant aspects of hictory, context, enviromment, and the like (kotter, 1978; Scott, 1977; Van de Ven \& Ferry, 1980).

These views of organizational effectiveness have problems of their own. First, to achieve generality these theories rely on very abstract theoretical notions of dubious applicability (discussions of uncertainty, technology, and the "fit" between them provide good examples) or they rely heasily on ad hoc bridging assumptions in applying more general theories to any particular case. Second, these theories frequently neglect the varied uses and meanings that more generally defined constructs have in particular settings. Thus, management information systems and computer technology may have the theoretical referent of reducing uncertainty, but the practical import (and meaning) of redistributing power in existing organizations (Gricar, 1979). Given the problems of defining and applying generally effective structures and processes, some authors have attempted to develop models of process and structure that are organization-specific, mainly operating as guides to diagnosis and change in particular systems.

\section{Organization-Specific Viess (Cell IV)}

As representative of the Cell IV approach, the focus is mainly on process-qualitative evaluations. The proces-qualitative evaluation has erolved as a response to the limitations of the outcome-oriented views of effectiveness, particularly their difficulties in specifying gencrally agreed-upon outputs meat sured in common metric (Weiss \& Rein, 1965). This approach consists essentially of information gathering to monitor the unfolding of a program as it is going on, noting particularly those events that ate critical, collecting documents, and observing the dfects of the program on institutions and individuals. This can provide the decision maker with informat tion ahout the variety of forms the program is taking in individual agencies of subunits, information that may be useful in understanding the impact of the program and in moditying policy.

Unfortunately, the features recommending this approach (flexibility, openness 10 information. adaplability) are the same features that encourage 
criticisms of it as being too diffuse, not resultsoriented, and having little prescriptive power. Moreover, theories of effective organizational operation, whether they are general or organization-specific, share a common set of problems.

The view that there are "effective" structures and processes rests on either extremely mixed and generally tenuous empirical support or on the firm belief that some structures must be effective in some sense. Second and more importantly, these examinations of the efficacy of organizational structure or process implicitly or explicitly assume that there is a "real" measure of effectiveness, measured or not. This belief is far from easy to confirm. Until some understanding of what the dependent variable is or means is reached, the tie of structure or process to it must remain unclear.

\section{Summary of Current Approaches}

Four major categories of approaches to organizational effectiveness were defined by the crossclassification of the dimensions of intended use (general or organization-specific) and focus (outcomes or processes and structures). Each has something to recommend it, and each has fostered good and useful research. At the same time, each has distinctive disadvantages, partly inherent, and partly owing to limitations in the state of relevant theory and empirical results.

Approaches aiming for general statements about organizational effectiveness in outcomes or processes gain scope and coverage at the expense of detailed applicability to given organizations. This gain in detail for organization-specific approaches allows identification of the multiple and possibly conflicting goals for the organization pressed by multiple constituencies. These approaches also are more able to unearth the multiple meanings and uses of organizational outputs and processes. These gains, however, tend not to be easily generalized. Approaches that focus solely on the outputs of the organization tend not to reveal how to make organizations more effective. Approaches focusing on processes and structures have a greater level of apparent instrumental utility at the expense of assuming the effectiveness of these processes or structures. A paradigm drawing on each of these theoretical perspectives will be proposed.

\section{An Example}

The Municipal Contruction Program in the U.S. Environmental Protection Agency (EPA) is used here as an example for a review of the application of the four generic approaches to organizational ef. fectiveness. One of the measures of effectiveness used for different programs in the federal sector is the productivity index calculated by the Bureau of Labor Statistics, which is calculated as the ratio of the sum of different weighted "outputs" of the program and the workyear "inputs" - a clear measure of general efficiency. The intended use of the index across offices and agencies is to get, in the aggregate, a measure of the productivity of the federal workforce. The productivity index, arguably, can be called a general measure of output (Cell I) for the program. Over a period of years, the index reports whether the productivity has increased or decreased and by what percentage. But the index has several limitations. It is far from inclusive of all the program activities; the outputs do not include factors such as quality and timeliness; the weights associated with the outputs are of questionable accuracy; and the index makes little effort to correct for changes in outputs or weights over time. Perhaps the most important limitation of the index is in its utility-from the figures, very little can be learned as to why productivity has changed. The index exists primarily for reporting, in an auditing sense, to the outside world. It does not, in fact, have much importance in influencing the behavior of organizational members.

Although the summary productivity index exists mainly for external consumption, the measures of outputs specific to the different categories in the program are considered useful and relevant internally (Cell II). In this case, it was observed that over a period of two years the number of categories and the weights associated with the outputs changed. Thus these outputs tell about the reorientation of goals and provide a picture of the unit's activities more closely in line with the unit's real situation.

For understanding the outputs and the changes in them, an examination is needed, not of the outputs themselves, but rather of the decision making and priorities within the agency, which are behind the planning and production of these outputs. Such an analysis would utilize a perspective of agencyspecific views of effective operation (Cell IV). It 
was discovered in interviews with key decision makers that this particular unit had been criticized within the agency for excessive reliance on getting contract dollars out and insufficient attention to whether the money was well spent. This criticism was reflected in the increased attention to certain outputs dealing with project completion.

None of the analyses discussed above would produce an accurate, useful picture alone. They lack the consideration of the general framework tying such decisions together, as represented by analyses focusing in general considerations of effective operation (Cell III).

Program objectives for the municipal construction program in the early years were found to reflect the organizational priorities of EPA at that time. EPA's early history was one of urgent activity to meet legislated program objectives-by and large, efficiency and cost effectiveness were criteria to be considered as secondary. As the early push for program objectives receded a bit, as oversight from various external bodies increased, EPA's decision making began to include consideration of the costs and cost effectiveness of its regulatory, enforcement, and construction activities. These changes filtered down to its different subunits and programs. Thus, the changes in the goals of the municipal construction program between two years can be viewed in the context of a changing notion of what effective federal programs are about in EPA and in government at large.

The case bears out that measures of effectiveness for the four generic approaches have one facet in common-they are accounts of those outputs and operations, and not the outputs or operations themselves. There is fairly extensive literature suggesting that organizations tend to tailor the accounts of their performance in different ways, depending on whether the measurements and reports are for external or internal consumption (Altheide \& Johnson, 1980; Boland, 1982; Edelman, 1977; Hopwood, 1972; Meyer \& Rowan, 1977; Wildav. sky, 1972). Thus it obviously is important to recognize that these accounts of outputs or behaviors are different from the outputs or behaviors themselves in several respects.

They are not the activities in all their complexity, but rather interpretive summaries of them, screening out irrelevant detail and highlighting important parts of the activity. Thus, the letter accompanying the data sent to the Bureau of Labor Statistics states:

We have. . deleted some last vear outputs that are no longer priority items. In their place we have added several new outputs. We believe the deletions and additions accurately reflect the agency's produclivity and program thrusts for the current year.

Moreover, the reports are not neutral constructions of events. They generally are constructed with an audience or purpose in mind. In the example given, the purpose was partly one of self-justification, and the audience was at least the Bureau of Labor Statistics, and possibly other oversight agencies in government as well. Thus, a foomote to the data states:

The new outputs (for the municipal construction program) reflect additional and more intensive analytical program efforts.

It was felt within and without the agency that this effort has been insufficient in the past in this program and needed to be emphasized.

It is also important to note that the weights in the formula for the productivity index were modified for the year that was reviewed. With the old formula, there would have been about a 30 percent decrease in productivity, as against the 12 percent increase reported with the new formula. It is not suggested here that the new formula was utilized to show better productivity-the program effort had shifted in emphasis and the figures should reflect this shift. It merely is noted that EPA was far from indifferent to the effects of these figures and wanted to get the best possible hearing for the program. This was particularly so given the level of criticism that had been levied against the program.

Finally, these accounts of outputs and activities differ from the outputs and activities themselves in that these accounts are created and received in the contexts of the creators and receivers, respectively. Changes in the intentions and circumstances of either sender or receiver change the character of the account.

In summary, the various approaches to effectiveness would each seek different measures of effectiveness relying on different sources of data. Moreover, each measure represents an account by the organization of itself and its activities. The different accounts are selective interpretations of events, have different aims and audiences, and are sent and received in different contexts. Given these differences in measures, data sources, and ac- 
counts. how can effectiveness be interpreted in any singular and useful way?

\section{The Paradigm}

\section{Perrow suggests:}

Instead of starting with a dependent variable that is a presumed public good and asking why we are getting it or not getting it, we should ask "who is getting what" from the organization or "effectiveness for whom?" The question presupposes a definition of organization that is different from that assumed by many schools of thought. If we define organizations. . as intentional human constructions wherein people and groups within and without the organization compete for outputs of interest to them under conditions of unequal power, we have posed the issue of effectiveness quite differently than in the other perspectives (1977, p. 101).

This political model of organizations has been ably championed by numerous authors (Abell, 1975; Crozier, 1964; Dalton, 1959; Pfeffer, 1978; Pleffer \& Salancik, 1974; Zald, 1970). In this perspective, the work that the organization does and the way it conceives of its work form part of both the means and the ends in a complex bargaining process. In this process coalitions of actors located within and without the organization forge implicit or explicit agreements on the strategy and tactics by which the organization's activities will be governed. Thus, one way to define effectiveness in organizations is not as a thing, or a goal, or a characteristic of organizational outputs or behaviors, but rather as a state of the relations within and among these coalitions. An effective organization is one that is able to create accounts of itself and its activities that relevant members of the dominan! coalition and the task environment find acceptable in light of these agreements.

The accounts may be for various purposes to var. ious audiences and for a variety of activities. In the present example, the municipal construction pro. gram was justifying its outputs to the Bureau of Labor Statistics and other external groups in a general way, and also its attainment of goals within the agency. It was noted that these goals changed in response to specific criticisms of the program and 10 changes in general notions of effective governmen: operations. A way to characterize the accounts that organizations and subunits make of themselves is presented in Figure 2 .

In the model the question of for whom the account is constructed-its audience-is shown in the columns. Organizations account for themselves in quite different ways, internally and externally. The formal structures, procedures, and even personnel frequently are different for these different audiences. Thus, in the example of municipal construction, accounts of program activities were in. tended for two constituencies-external ones, in the form of the productivity index and the general com. mitment to increasing the cosi effectiveness of programs; and internal ones, in the program's specific output goals and changing those goals to account better for the costs and effects of the program.

The second major dimension of organizational accounting is based on the character of the activity accounted for. Some organizational activities are in the nature of creating frameworks. Others are operational or in the nature of performing within the

\section{Figure 2 \\ Organization's Accounts of Itself}

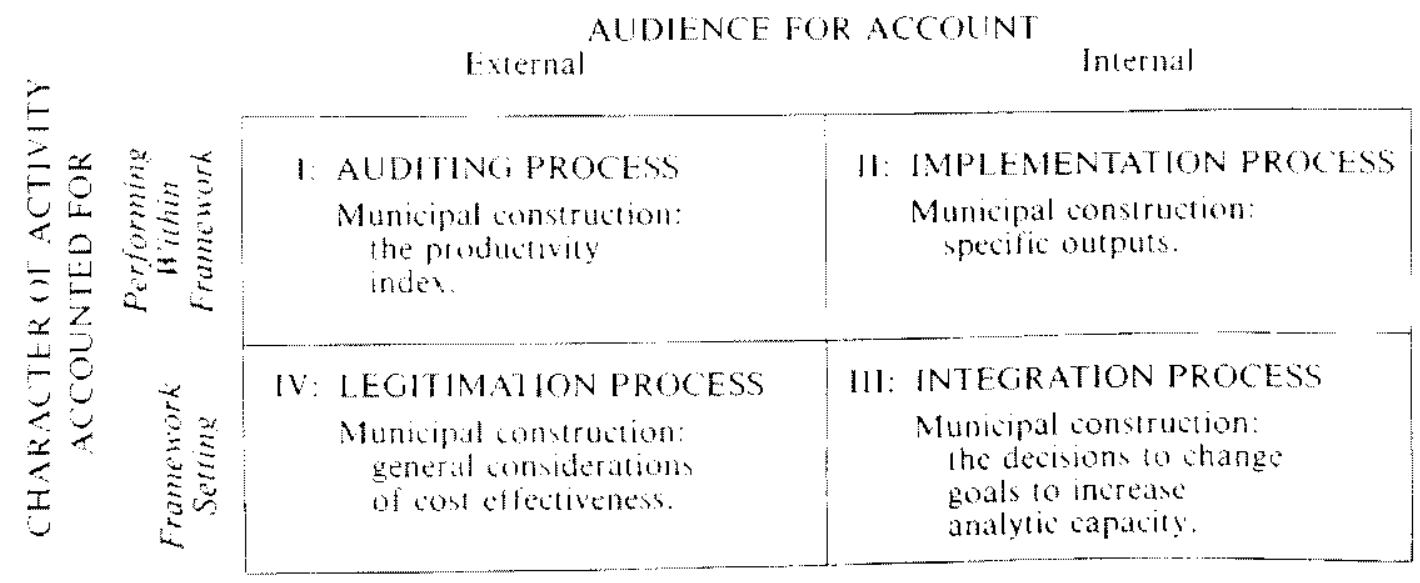




\section{framework.}

The management decisions concerning planning, staffing, acquisition and allocation of resources fall into the category of framework creation. The symbolic governance of organizations and the political process of aggregating varied interests of organizational parties into a sense of mission and communicating that mission internally and externally also are framework setting. For the municipal construction program, these decisions included the general and specific decisions to increase analytic capacity in this program and programs like it in line with organizational priorities and goals. By contrast, performing within the framework relies on these framework setting decisions and translates them into output oriented action. For the municipal construction program these outputs were measured by the general productivity index and the specific outputs that form the overall index.

This model ties rather directly to the earlier discussion of perspectives on organizational effectiveness. Accounting for outputs to external sources generally takes the form of general output measures (the productivity index). By contrast, internal accounting for outputs generally is of the form of organization-specific output measures (attainment of specific output goals). The organization, however, must account for itself not only in terms of specific outputs, but also in terms of its approach to general and specific decisions. Thus the decision to increase the analytic capacity of the municipal construction program was an organization-specific decision about effective operation that was intimately tied to effectiveness. This decision, however, was associated with a more general commitment to cost effective operations for external consumption.

Thus, each of the four perspectives on organizational effectiveness can be seen to focus on measures of a particular kind of activity intended for a particular audience. One advantage of a more inclusive perspective is that it allows discrimination among these different measures and shows how they are linked in the activities of a given organization.

The cross-classification of the dimensions of audience and activity leads to four categories of organizational accounting. In the model an example for the Municipal Construction Program has been presented in each quadrant. The processes in quadrants 1 to 4 have been referred to as auditing, im- plementation, legitimation, and integration, respectively.

Accounting for external consumption (related to outputs) is referred to here as "auditing." This category is by far the most frequently seen form of justification activities - reports to Congress, regulatory agencies, and so on. Such reports generally contain much bottom line information in terms of countable, attributable outputs. Frequently these indices are not those against which the organization actually measures its activities internally.

Performances that may appear quite satisfactory relative to public goals may be unsatisfactory from the perspective of what have become internally operative goals or the reverse. In fact, standards against which performance is reported to the external environment may not have much meaning within the organization. And because performance within the organization is not evaluated by these external standards, they do not have much direct inMuence on the behavior of the organizational actors.

The implementation process involves self-analytic accounts and includes information on activity or output quality, value, or efficiency. These contain departmental or individual performance evaluations. These accounts probably are neither more nor less likely to be truthful than accounts of outputs produced for external audiences. They are. however, more likely to be influential day to day and of a qualitatively different form than those intended for external consumption.

The third process covers the way in which the organization accounts for itself in framework setting terms in its external constituents. This accounting is referred to a legitimation. This form of account assists and/or seeks support for organizational activities of a framework setting sort, justifying or promising not a particular product but rather a particular role, asserting not a thing done, but a capacity or need to be able to do that thing and other things like it.

The integration process refers to internal accounts of framework setting activities that are very important within the organization, because through these activities the internal management of organization is conducted. The work of integrating programs, deciding which will be given resources and which will have resources taken away and the process that underlies these decisions-that is, the 
operation of the organization's internal political economy-is accounted for in this way. Of the four activities, integration probably is the least frequently accounted for in a formal way. It does not produce many tangible outputs.

There are several different sorts of linkages among elements in the model. First, there are the legitimation and auditing accounts that organizations make to actors outside the organization. The linkage between these organizational accounts and environmental expectations often is associated with the organization's justifications for past activity or attempts to secure future support. It also is associated with attempts by actors in the environment to monitor and direct organizational activities. This linkage not only serves to clarify the demands of the environment on the organization's outputs and decision making, but it also serves as the main conduit for the organization's attempts to manage its environment (Aldrich \& Pfeffer, 1976; Child, 1972; Pfeffer \& Salancik, 1978). It is possible that through missed communication, design or environmental or organizational change, the organization's accounts and expectations of the environment will fail to correspond.

A second sort of linkage can be focused in each quadrant of the model. This linkage relates work processes and activities to accounts of them in each quadrant. Here again, when theory in use departs from the espoused theory (Argyris, 1970), there is a high likelihood that work activities will differ from accounts of them. These mismatches may result from goal displacement (Merton, 1957) or from design.

A third set of linkages relates the different kinds of accounts to one another. It is suspected that accounting related activities tend to follow a cycle either from the upper left box (auditing) through the lower left box (legitimation) clock-wise, or in the reverse sequence from legitimation to auditing, counterclockwise.

The first set of changes discussed in the municipal construction program between the two years began in the legitimation phase. Criticism of EPA's and other regulatory agencies' neglect of cost effectiveness in program operations had led to a widespread push for regulatory reform. This was translated as an internal consideration in the decision to increase the analytic capacity and to change the goals of the program (the integration phase), which led to a reformulation of the program's internal goals and outputs (the implementation phase). This, in turn, led to a new set of outputs to be reported to the Bureau of Labor Statistics (the auditing phase).

The more recent changes in the municipal construction program operated in the reverse fashion. Congress and the Administration, through the budgetary process, made it clear that the construction of municipal waste treatment facilities was not a priority any longer (the auditing phase). This was translated into new goals for the program internally (implementation) and new models for the effective operation of the program (integration). It is far too soon to tell what effect these changes have on the more general considerations of effective agency operations (legitimation).

It should be noted, however, that the accounts and processes in the paradigm need not be so closely connected. The mission of the organization ex. pressed in legitimation processes may be very different from the outputs for which the agency is held accountable. Such was argued to be the case for the Headstart program (Deutscher, 1977). This discrepancy may, but need not, be a stimulus for change. As Weick (1976) argued, this loose coupling provides a source of organizational stability.

To summarize, in this paradigm four relatively distinct-though interrelated-spheres of organizational accounts have been proposed. These correspond to the four generic approaches to studies of organizational effectiveness developed earlier in the paper. Clearly, any comprehensive attempt to as. sess organizational effectiveness will consider both output and process, in both internal and external accounts.

\section{Assessing Organizational Effectiveness}

The worth of the approach to effectiveness of fered here probably is best seen in the new questions it encourages. The paradigm proposed suggests two broad classes of questions not generally asked in assessing the effectiveness of a particular organiza. tion or subunit. First, what are the various accounts that the organization makes of its activities? What activities are being accounted for and to whom? How are these accounts changing over time? Second, how do these accounts mesh with the expectations of actors in the task environment, with the 
processes the accounts are supposed to represent, and with other accounts? Outlined are some tentative methodologies that may be helpful in pursuing answers to these questions.

Accounts of terminal outputs prepared by the organization for external audiences, auditing accounts, are a sensible place to begin in assessing organizational effectiveness. For most organizations these are available through printed reports or as outputs of ordinary accounting functions. They must, however, be carefully interpreted. First, one must find out whether the outputs selected as critical are of major interest to the organization, or to some particular set of its constituents, or in fact to no one. Second, if informal or implicit goals and outputs emerge in the course of data collection, attempts should be made to generate accounts of these as well. Third, one must be sensitive not only to changes in the levels of outputs, but to qualitative changes in the outputs themselves.

For accounts of terminal outputs generated for internal use, implementation accounts, some of these questions are of lesser importance. Because the organization generally selects these outputs or goals, they are less likely to be arbitrary or irrelevant to the organization. These goals, however, may be of different importance in motivating member behavior, and they may change over time.

The proposed paradigm suggests two accounts of organizational activities other than those of terminal outputs for internal and external consumption just described. These include accounts of the integration process, which covers decisions that allocate resources and prioritize activities within programs and that reorient ongoing activities and programs. Moreover, explanations for some of these specific decisions rest in the most general assumptions and philosophies about what constitutes effective management; these represent accounts of the legitimation process.

Accounts of the auditing and implementation processes generally are available in the organization's printed reports or are available as outcomes of standard accounting practices. In fact, the major branches of accounting-financial and cost (or management) accounting - are associated with accounting for external and internal purposes, respectively. Accounts of legitimation and integration processes, by contrast, are not generally collected in most organizations and probably would have to be gathered through interviews, meetings, or other face-to-face techniques. Accounts of the former, general views on effective operation, will be particularly difficult to tease out. These views will involve questions of "ideas in good currency" and broad managerial strategy. As an example, a broadly held view within the organization could be, "In the long run, no cost is too high for a clean environment." Or it could be, "A clean environment is desirable; but it must be an economic proposition." It can be seen that organizational choices would be influenced by which of these ideas is in good currency. These are unwritten criteria used by the organization to test solutions. At choice points, elimination of some alternatives takes place on the basis of such assumptions and sentiments-certain possibilities and directions are not just considered because they do not fit with organizational sentiments or mission.

In sum, the assessment of organizational effectiveness rests not simply on how much of particular outputs is being produced, but also on the decision making that sets the framework in which the production of these outputs is carried out. These latter accounts are not generally available. They usually must be gathered through face-to-face methods.

Effectiveness also rests on the extent to which these accounts mesh with the environment, with the processes they are supposed to represent, and with each other. Assessing the linkages among these various elements presents particularly difficult methodological problems. Rather than speaking more generally about the organization's ability to preserve or affect its environment or to integrate its activities internally, tracking specific issues and decisions through the organization's decision making and production processes will generate the detail and interpretation necessary. Here Scriven's (1959) "modus operandi" approach and the techniques of process oriented qualitative evaluation seem appropriate. Common to these approaches is an emphasis on finding out how a particular decision or issues interpreted in various sectors and levels of the organization. This sort of information is most easily collected through repeated interviews with officials who had some part in handling these decisions.

To be sure, collection of data relating to accounts in each of the four quadrants suggested by the paradigm and the linkages between them is sufficiently difficult that for any large organization it 
would be a massive undertaking. In most organizations a sensible alternative would be to focus on particular activities, programs, or subunits of interest. It might seem that such intensive investigation of only a few parts of an organization places severe limitations on the generality of findings obtained. This objection does not seem particularly compelling for several reasons. First, more global coverage that attends only to terminal outputs probably provides less generally useful results. Although the specific outputs of an organization or subunit might be unique, many of the management and work processes it utilizes are common to many organizations. A less labor-intensive approach of collecting and tabulating unique organizational outputs tells little about the more common tasks of organizations and their members.

Second, perfect measures of effectiveness are not as significant as are changes in effectiveness and what caused or could cause them. Such knowledge is furthered best by detailed knowledge of the organizational processes that translate environmental demands into various administrative and production processes and accounts of them. The para- digm proposed is intended to provide just such knowledge.

\section{Discussion}

The approach to assessing organizational effectiveness presented here has several advantages over existing approaches. The model allows an examination of both outputs and processes in a critical and holistic way, and it recognizes the roles of each and the linkage between them as critical to effectiveness. Effectiveness in the model is seen less as an end state than as a continuous process relating the organization to its constituents. Finally, with the focus on processes common to many organizations rather than outputs unique to each of them, the results obtained can be both plausible and useful.

To be sure, there are limitations to the approach suggested. It is expensive in terms of time and effort, and it does not produce global conclusions easily. It can, however, produce rich and useful assessments of organizational outputs and processes that do justice to the variety and complexity of organizational life.

\section{References}

Abell, P. Organizations as hargaining and influence systems. New York: Halsted Press, 1975.

Aldrich, H. E. Organizations and environments. Englewood Cliffs, N. J.: Prentice-Hall, Inc., 1979.

Aldrich, H. E., \& Pfeffer, I. Environments of organizations. Annual Review of Sociology, 1976, 79-105.

Altheide, D. L., \& Johnson, J. M. Bureaucratic propaganda. Boston: Allyn and Bacon, 1980.

Argyris, C. Intervention theory and method: A behavioral science view. Reading, Mass.: Addison-Wesley Publishing Co. 1970

Bardach, E. The implementation game: What happens after a bill becomes a law. Cambridge, Mass.: The MIT Press, 1977.

Blake, R. R., \& Mouton, J. S. The managerial grid. Houston, Tex.: Gulf Publishing Co., 1964.

Boland, R. J. Myth and technology in the American Accounting profession. Journal of Management Studies, 1982, 109-127.

Chandler, A. D. The visible hand. Cambridge. Mass.: Harvard University Press, 1976.

Child, J. Organization structure, environment, and performance - The role of strategic choice. Sociology, 1972, 6, 1-22.

Crozier, M. The bureaucratic phenomenon. Chicago: University of Chicago Press, 1964.
Dallon, M. Men who manage. New York: John Wiley \& Sons, Inc., 1959.

Deutscher, 1. Toward avoiding the goal trap in evaluation research. In F. G. Caro (Ed.), Readings in evaluation research. New York: Russel Sage Foundation, 1977, 221-238.

Edelman. M. Polirical language: Words that succeed and policies that fail. New York: Academic Press, 1977.

Etzioni, A. Modern organizations. Englewood Clifs, N. J.: Prentice-Hall, Inc., 1964.

Fiedler, F. E., \& Chemers, M. M. Leadership and effective management. Glenview, Ill.: Scott, Foresman and Company, 1974.

Friedlander, F., \& Pickle, H. Components of effectiveness in small organizations. Administrative Scjence Quarterly, 1968. 13, 289-304.

Galbraith, J. K. Designing complex organizations. Reading. Mass.: Addison-Wesley, 1973.

Galbraith, J. K. The new industrial state. Boston: Houghton Mifflin, 1967.

Granick. D. Soviet metal fahricating and economic development: Practice versus policy. Madison: The University of Wisconsin Press, 1967. 
Gricar, B. G. Environmental imperatives created by government regulation: Predicting organizational response. Unpublished doctoral dissertation, Case Western Reserve University, 1979.

Hannan, M. T., \& Freeman, I. Obstacles to comparative studies. In P. S. Goodman \& J. M. Pennings (Eds.), New perspectives on organizational effectiveness. San Francisco: Jossey-Bass, 1977, 106-131.

Hannan, M. T., \& Freeman, J. H. The population ecology of organizations. In M. W. Meyer (Ed.), Environments and organizations. San Francisco: Jossey-Bass, 1978, 131-171

Hopwood, A. G. An empirical study of the role of accounting data in performance evaluation. Empirical research in accounting (supplement to the Journal of Accounting Research), $1972,10,156-182$.

Kahn, R. L. Organizational effectiveness: An overview. In P. S. Goodman \& J. M. Pennings (Eds.), New perspectives on organizational effectiveness. San Francisco: Jossey-Bass, 1977, $235-248$.

Kepner, C., \& Tregoe, B. The new rational manager. Princeton, N. J.: Princeton Research press, 1981.

Kotter, J. P. Organizational dynamics: Diagnosis and intervention. Reading, Mass.: Addison-Wesley Publishing Co., 1978.

McGregor, D. The human side of enterprise. New York: McGraw-Hill, 1960.

Mckelvey, B. Organizational speciation. In C. Pinder \& L. Moore (Eds.), Middle range theory and the study of organizations. Boston: Martinus Nijhoff, 1980, 169-186.

Merton, R. K. Social theory and social structure. Glencoe, Ill: Free Press, 1957.

Meyer, J. W. \& Rowan, B. Institutionalized organizations: Formal structure as myth and ceremony. American Journal of Sociology, 1977, 83, 340-363.

Perrow, C. Organizational analysis: A sociological view. Belmont, Cal.: Wadsworth Publishing Co., Inc., 1970.
Perrow, C. Three types of effectiveness studies. In P. S. Good. man \& J. M. Pennings (Eds.), New perspectives on organizational effectiveness. San Francisco: Jossey-Bass. 1977, 96-105.

Pfeffer, J. Organizational design. Arlington Heights, III.: AHM Publishing Corporation. 1978

Pfeffer, J. \& Salancik, G. R. Organizational decision making as a political process: The case of a universicy budget Administrative Science Quarterly, 1974, 19, 135-151

Pleffer, J., \& Salancik, G. R. The external control of organizations: A resource dependence perspective. New York: Harper \& Row, 1978.

Price, J. L. Organizational effecriveness. Homewood. Ill.: Ir. win, 1968.

Scott, W. R. Effectiveness of organizational effectiveness studies. In P. S. Goodman \& J. Mi. Pennings (Eds.), New Perspectives on organizarional effecriveness. San Francisco: Jossey-Bass, 1977, 63-95.

Scriven, M. Explanation and prediction in evolutionary theory. Science, $1959,130,477-482$.

Van de Ven, A. H. \& Ferry, D. L. Measuring and assessing organizations. New York: Wiley, 1980

Weick, K. E. Educational organizations as loosely coupled systems. Administrative Science Quarterly, 1976, 21, 1-19.

Weick, K. E. The social psychology of organi-ing. Reading. Mass.: Addison-Wesley, 1979.

Weiss, R. S., \& Rein, M. The evaluation of broad aim programs: A cautionary case and a moral. The Annals of American Academy of Political and Social Science, September 1969. 133. 142

Wildavsy, A. B. The self-evaluating organization. Public $4 d$. ministration Review, 32, 509-520.

Zald, M. N. Political economy: A framework for comparative analysis. In M. N. Zald (Ed.), Power in organizations. Nashville, Tenn.: Vanderbilt University Press, 1970. 221-261.

Gregory H. Gaertner is Assistant Professor of Organizational Behavior in the Weatherhead School of Management, Case Hestern Reserve University.

S. Ramnarayan is an Advanced Doctoral Student in the' Department of Organizational Behavior, Case Western Reserve University. 
Copyright of Academy of Management Review is the property of Academy of Management and its content may not be copied or emailed to multiple sites or posted to a listserv without the copyright holder's express written permission. However, users may print, download, or email articles for individual use. 